\title{
A utopia da Reforma Sanitária Brasileira em um discurso no Congresso da ABRASCO 2009
}

The utopia of the Brazilian sanitary reform in a speech at ABRASCO's Congress 2009

Luis Rogério Cosme Silva Santos'1, Tiago Parada Costa Silva²

Doutorando em Saúde Pública pela Universidade Federal de Minas Gerais (UFMG) - Belo Horizonte (MG), Brasil. Professor da Universidade Federal da Bahia (UFBA) Vitória da Conquista (BA), Brasil. luisrogerio.ufba@gmail.com

2 Mestre em Saúde Coletiva pela Universidade Federal da Bahia (UFBA) - Salvador (BA), Brasil. Sanitarista da Secretaria da Saúde do Estado da Bahia - Salvador (BA), Brasil.

tgparada@yahoo.com.br
RESUMO Este texto procura analisar o conteúdo da conferência proferida pelo professor baiano Jairnilson Paim, no IX Congresso Brasileiro de Saúde Coletiva, realizado em Recife (PE), em 2009. Traz à baila discussões sobre a importância do pensamento utópico na definição de um novo paradigma no campo da pesquisa acadêmica, proposto por diversos autores, visando à práxis em favor da consolidação do Sistema Único de Saúde (SUS) e do resgate de princípios e condutas que nortearam o processo da Reforma Sanitária Brasileira (RSB), como conquistas da sociedade organizada.

PALAVRAS CHAVE: Utopia; Reforma Sanitária; Práxis, Sistema Único de Saúde.

ABSTRACT This text looks for to analyze the content of the conference pronounced for the bahian professor, Jairnilson Paim, in IX the Brazilian Congress of Collective Health, carried through in Recife (PE), in 2009. Evidences the current debate on the importance of the utopian thought in the definition of a new paradigm in the field of the academic research, considered for diverse authors, aiming at the praxis for the consolidation of the Brazilian Health System and of the rescue of principles and behaviors that had guided the process of Brazilian Sanitary Reform $(R S B)$, as conquests of the organized society.

KEYWORDS: Utopia, Public Health Reform, Praxis, Unified Health System. 


\section{Construindo o cenário}

No Teatro Guararapes, localizado no Centro de Convençóes de Recife, no dia 04 de novembro de 2009, durante o IX Congresso da ABRASCO, o professor baiano Jairnilson Paim, inspirado na composição musical de Torquato Neto e Jards Macalé, caminhou lentamente em direção ao microfone, de onde propôs-se a 'desafinar o coro dos contentes'. Em pauta, o tema 'Reforma Sanitária Brasileira: uma promessa não cumprida?'. Destaca-se que esta preleção ocorreu um dia depois do discurso proferido pelo presidente Lula, no mesmo lugar.

O teatro, cujo nome retrata uma batalha historicamente importante no contexto da emancipação brasileira, tem capacidade para assentar 2.405 pessoas e acomodou gente pelas escadarias laterais e centrais, todos curiosos para ouvir a conferência polêmica e esclarecedora de um dos mais críticos e ativos sanitaristas da atualidade no que concerne à 'ideia', ao 'movimento', à 'proposta', ao 'projeto' e ao 'processo' da Reforma Sanitária Brasileira (RSB). Fato intrigante, uma vez que, durante o congresso, somente o presidente Lula teria enchido o plenário daquele modo.

Mas, naquela manhã de quarta-feira, algo ensaiava ser diferente, ampliando o interesse das pessoas, visto que, em 2009, o Conselho Nacional de Saúde e o Ministério da Saúde, juntamente com as entidades representativas dos secretários municipais e estaduais de saúde, organizaram as caravanas em 'defesa do SUS', com a participação dos estados. Defender o SUS do quê? De quem? Que novas e antigas ameaças rondariam esse sistema? Seriam essas indagaçóes que o sanitarista poderia esclarecer em sua conferência?

Em pé, com as mãos sobre a tribuna posta do lado esquerdo do palco, que mede $1.050 \mathrm{~m}^{2}$, por vezes, com a sua perna esquerda flexionada para trás do joelho direito, aparentando, com esse gesto e pelo tom da voz, certa tranquilidade, Paim, ao discorrer sobre a 'revolução passiva' e sobre o 'transformismo político' que afeta a política de saúde no País, destilou, homeopaticamente, para uma plenária repleta, o referencial de um dos seus mais recentes trabalhos: 'Reforma Sanitária: Contribuição para a compreensão e crítica'.
Sob a luz do marxismo e das ideias de Gramsci, o preletor se permitiu buscar, como referencial, além de figuras de pensamento destacado no meio acadêmico, a inspiração textual e poética de Torquato Neto, Carlos Drummond de Andrade e João Cabral de Melo Neto, entre outros, resgatando a importância, ao mesmo tempo, do sonho, da abstraçáo, da práxis, do pensamento e da ação como estratégias para explicar por que a reforma sanitária não avançou e se desfigurou no Brasil no transcorrer da redemocratização, a partir de 1985.

Paim analisou o modo como cada governo, na fase republicana, a partir de 1995, de Sarney a Lula, tratou a proposta da RSB, e o risco de um retrocesso na implementação do Sistema Único de Saúde (SUS), como uma conquista social e política.

Sua fala foi na direçáo do resgate de um sonho. Aquele contido no Manifesto da Reforma Sanitária, divulgado em Brasília, em 23 de novembro de 2005, reafirmando o compromisso com a saúde dos brasileiros. O sonho manifestado várias vezes pelo movimento do Centro Brasileiro de Estudos de Saúde (CEBES), do qual é membro fundador.

Diante de uma plenária lotada de pesquisadores, o professor baiano esforçou-se para manter o nível científico da conferência, mas, era nítida a contradição entre a postura do pesquisador metodologicamente cauteloso e a do militante angustiado, "apaixonado (não só pelo saber em si, mas também pelo objeto do saber)", como escreveu Gramsci (1999), por ele citado, assim acreditando que

\section{[...] o intelectual possa ser um intelectual (e não um mero pedante), mesmo quando distin- to do povo-nação, ou seja, sem sentir as pai- xóes elementares do povo, compreendendo-as $e$, portanto, explicando-as e justificando-as em determinada situação histórica. (GRAMSCI, 1999, p. 222 apud PAIM, 2008, p. 21).}

Se o discurso do presidente Lula arrancou aplausos calorosos no dia anterior, em função do carisma e do caráter sempre político e estratégico de seus gestos e palavras, foi algo surpreendente constatar que o professor Paim também fora aplaudido efusivamente, quando, 
em sua 'aula' sobre 'história e política de saúde', tratou, entre outras coisas, da utopia e de valores éticos praticamente exauridos na sociedade pós-moderna de economia neoliberal, que, de forma conservadora e autoritária, reluta em permitir à sociedade brasileira o pleno direito constitucional a uma saúde universal, integral e de qualidade, constituída a partir de princípios democráticos e socializantes.

Num momento histórico no qual o passado perde sentido, a luta de classes é ocultada e o trabalho se desconfigura como elemento constitutivo da identidade do ser social, aquela conferência, se fosse considerada somente um conjunto de ideias limitadas a um método ou a uma técnica, talvez não causasse tanto alvoroço e reflexôes no público. No momento atual, quando muitos intelectuais optam por ficarem mudos ou escondidos atrás dos muros da academia, temendo retaliaçóes daqueles que ocupam funçôes estratégicas nas diversas esferas do poder, o que a saúde pública precisa é de seres utopicamente desligados de certos valores hegemônicos, e que tenham a capacidade e a coragem de dizer que não se pode mais, no que se refere à política de saúde, caiar o sepulcro diante de certos riscos de retrocesso.

Em um gesto audacioso e contra-hegemônico, o professor baiano descortinou a inércia e questionou a robustez das regras instituídas pela lógica do mercado, em favor de uma nova postura em defesa do SUS e do resgate de princípios e valores inerentes à Reforma Sanitária Brasileira.

\section{A natureza política do discurso utópico e o conflito ideológico}

Paim entrou no Teatro Guararapes, em Recife (PE), com uma postura semelhante a de um gladiador que sabe que pode obter lesóes, mas sabe, como ninguém, como bater numa fratura exposta. Imbuído da austeridade de quem sente a responsabilidade pelo contexto que envolve a Reforma Sanitária Brasileira, disparou: "Se o governo Fernando Henrique quebrou os músculos do Estado, o governo Lula quebrou os músculos da sociedade!" (OLIVEIRA, 2009). Da frase ficou, entre outras reflexóes, a certeza de que a saúde e o controle social ainda estão na condição de direito, e não na condição de exercício. Tal postura nos remete a questionar, não obstante os avanços do SUS, se a RSB não estaria plenamente consolidada. A resposta é 'não', uma vez que requer mudanças estruturais, redução ou eliminação da desigualdade socioeconômica. Alguns avanços conquistados até aqui não se refletiram na eliminação de determinantes e condicionantes do processo saúdedoença, e, por consequência, na atenção integral às necessidades sociais de saúde da população.

Como o presidente Lula, na noite anterior, o professor baiano se protegeu atrás de sua história de vida, de pesquisador que respeita o método, passando, por isso, ileso pela crítica científica, para demonstrar o quanto o seu lado militante consciente, dentro e fora da academia, pode incomodar as estruturas conservadoras, cujos agentes sociais se esforçam para minar a proposta da reforma sanitária, a partir da vulnerabilidade política e social do sistema que deve promover a saúde.

É provável que não se trate apenas de um ensaio, mas de uma ofensiva do capital, em direção à saúde como direito do cidadão e dever do estado, ou seja, contra a natureza socializante da RSB e do próprio SUS, como parte disso. Alguns componentes do tão comentado 'Ato Médico' não seriam um exemplo desse retrocesso? Não estaria aí embutido o retorno ao sujeito hegemônico no campo da saúde, na contramão do novo modelo assistencial que se pretende sedimentar com ênfase na equipe multiprofissional e multidisciplinar em saúde? As terceirizações das instituições públicas para a iniciativa privada representam a certeza de um melhor desempenho do sistema universal e igualitário?

Pelo exposto por Paim, pode-se constatar que os agentes ligados à lógica do complexo médico-industrial (PAIM, 2009) só consentem que o estado promova 'uma reforma parcial' do sistema de saúde (limitando-se a atuar sobre sistemas de serviços de saúde), por meio de uma 'revolução passiva', que ocorre quando a classe dominante consegue, estrategicamente, impôr-se através daqueles que momentaneamente estâo no poder (PAIM, 2008).

Levando-se em conta o conceito de reforma exposto por Pedro Demo como a "resposta usual a mazelas institucionais que o tempo inevitavelmente acarreta", 
ou mesmo o conceito de 'posição reformista', que, segundo o mesmo autor é "[...] marcada pelo interesse em mudanças dentro do sistema, partindo-se de que o sistema ainda deva ser preservado" (DEMO, 1987, p. 77), vê-se que a proposta da RSB tem em seu íntimo um traço processual mais reformador do que reformista, pois, a promoção da saúde e o foco na atenção primária, no contexto das redes de atenção à saúde, implicam mudanças estruturais significativas no sistema como um todo.

Tais mudanças não podem prescindir da luta contra as desigualdades sociais e territoriais, que afetam as relaçóes de classe em uma sociedade capitalista, que recentemente viveu, acrescente-se, mais de duas décadas sob uma ditadura militar, o que favoreceu as centralizaçóes do poder decisório e da riqueza.

Pautando-se ainda em Demo (1987), fica evidente a atualidade e a força da aula de Jairnilson Paim no Congresso da Abrasco 2009. A reforma sanitária defendida pelo conferencista, como processo, vai justamente em direção ao pensamento de Demo quando este diz que a

\section{[...] revolução propriamente dita é aquela} 'infra-estrutural', elaborada no longo prazo, como foi, por exemplo, a revolução industrial. (DEMO, 1987, p. 76).

E vai além:

\section{[...] ainda há a possibilidade histórica de} que, na sequência de um acúmulo de reformas, desabroche uma revolução. (DEMO, 1987, p. 77).

O que chamou a atenção na abordagem pública de Paim foi uma preocupação com o retrocesso, mesmo acreditando utopicamente que a reforma sanitária não pode ser parada por tratar-se de uma conquista e de uma necessidade social, trazendo no seu cerne um conflito ideológico contagiante, ainda que se dê no plano do inconsciente coletivo.

A característica superficial e pouco revolucionária das propostas dos governos republicanos, pós
1984, para a gestão do SUS e do trabalho na saúde, integrou o conteúdo da conferência. $\mathrm{O}$ conferencista apontou prováveis causas para esses efeitos, tendo a sua exposição cortada por aplausos quando citou Coutinho (1985), trazendo à baila o jogo político que interfere nas políticas de saúde:

O transformismo é um fenômeno associado à revolução passiva quando certos partidos (ou agentes) se unificam, mudando de lado, e reforçam posiçôes conservadoras das forças da ordem estabelecida, seja assimilando fraçôes das classes dominantes, sejam cooptando setores das classes subalternas. (COUTINHO, 1985 apud PAIM, 2008, p. 45).

Nesse aspecto, a releitura de Freire (1982, p. 79) faz-se oportuna remetendo-nos à compreensão de que a utopia é algo que "[...] tende ao dinâmico e não ao estático; ao vivo e não ao morto; ao futuro como desafio à criatividade humana e não ao futuro como repetição do presente [...]". Na pós-modernidade, utopia é sinômino de inconformismo e de ousadia.

\section{O sanitarista e Hitlodeu: cinco séculos de utopia}

O lugar e o tempo foram bem aproveitados pelo professor baiano para exposição de sua análise sobre a Reforma Sanitária Brasileira, uma vez que o debate sobre intervençôes necessárias no campo da saúde, com quem mantém posturas ortodoxas, pode parecer improdutivo. Afinal, como adverte Hitlodeu, personagem central do livro de Thomas More, (Utopia, do século XVI), nem sempre é aconselhável propor aos que estão no poder decretos justos: "Julgais que não me escorraçará ou fará de mim objeto de riso?" (MORE, 2008, p. 45). Daí, a importância para o mestre da 'Utopia' de dizer a verdade sempre onde ela possa ser ouvida. Paim ouvira, ao pensar a sua explanação em favor da RSB, a exclamação/indagação de Hitlodeu: 
Ora, dizei-me se eu fizesse estas e outras afirmaçóes, no meio de homens absolutamente dispostos a princípios opostos, não seria o mesmo que falar para surdos? [... Essa é a minha idéia quando vos dizia que a filosofia não tem assento entre os reis. (MORE, 2008, p. 45).

Como sanitarista, Jairnilson Paim demonstrou a força de um sonho no campo da saúde e a capacidade desse sonho de irradiar-se para outros setores da vida social, uma vez que a saúde pressupóe qualidade de vida, e que a RSB carece agora de novas mãos e mentes para tocá-la adiante, porque do outro lado as forças do capital se organizam para fragilizar o sistema.

A redemocratização do Brasil deixou uma sensação de vazio, principalmente nas novas geraçóes, como se não houvesse nada mais por fazer. $\mathrm{O}$ discurso neoliberal de que a 'história acabou' contribuiu muito para esse estado de apatia em relação à participação cívica e à qualidade dessa participaçáo, tâo importante para o desempenho institucional e dos governos no que se refere a políticas públicas, como asseveram Putnam, Leonardi e Nanetti (2005).

A participação, como escreve Demo (1987, p. 17),

\section{[... é a melhor obra de arte do homem em sua} história, porque a história que vale a pena é a participativa, ou seja, com um teor menor possivel de desigualdade, de exploração, de mercantilização, de opressão.

Os privatizadores da saúde, os terceirizadores da força de trabalho na saúde, aproveitam bem esse vácuo e, não podendo atacar abertamente o direito à saúde, propagam a ineficiência administrativa do SUS (ou das unidades do SUS), que 'precisaria' da lógica do capital privado, e de seus métodos administrativos, para qualificar a oferta de serviços e atender as necessidades de saúde dos brasileiros. Será?

Considerando que a proposta da RSB apresentada pelo professor Paim implicaria em reforma mais ampla de natureza transetorial, é notória a responsabilidade que cada agente social (estudantes, profissionais de saúde, políticos, trabalhadores) têm a desempenhar nesse processo de lutas emergentes, visando a frear a desestruturação do sistema, uma vez que, por mais que as forças hegemônicas tentem conter o avanço do SUS, dentro ou apenas influenciando os que estáo no poder, "a arte qualitativa do homem é a sociedade desejável que ele é capaz de criar" (DEMO, 1987, p. 17), e a luta na saúde sempre foi uma estratégia política para uma sociedade melhor, equânime, e, por consequência, com justiça social.

É imprescindível que, no ciclo apresentado por Paim para descrição e análise da RSB, que vai da 'ideia' até o 'processo', novos movimentos acorram nessa direção. Então, algumas questóes que se impóem são: Como motivar as pessoas a ponto de entenderem a participação cívica como necessidade, se essa participação tem relação com a trajetória histórica e social dos agentes envolvidos? Como encontrar o caminho para um sonho, quando muitos acham que o SUS está consolidado e o sonho acabou? Como sinalizar, numa sociedade cada vez mais materializada e individualizada, que a utopia não é algo sem sentido?

Thomas More esqueceu-se de perguntar ao seu personagem Hitlodeu: "Em que parte do Novo Mundo se situa a Utopia? Preferiria ter perdido todo o meu dinheiro a ter-me esquecido deste pormenor [...]" (MORE, 2008, p. 15). Com essa postura, Thomas More nos remete à conclusão de que a utopia (como a reforma sanitária e o SUS) é uma questão de certos princípios e valores imateriais e não propensos à barganha sob pena de comprometer o pacto e a ética sociais.

Pouca gente no mundo acadêmico póe em risco a sua paz individualizada, a sua condição econômica, a sua estabilidade de pesquisador em busca de certos princípios relevantes, como sinalizou More (2008). Paim, entre outras coisas, ao citar os poetas brasileiros, evidenciou que a utopia está na mente emancipada daqueles que desafinam 'o coro dos contentes', que vão se tornando 'anjos tortos' na vida; que são, acima de tudo, insistentes, como 'pedras no caminho'. A atitude crítica do professor nos remete ao ensino proposto por Freire (2008):

Não há ensino sem pesquisa e pesquisa sem ensino. Esses que-fazeres se encontram um no corpo 
do outro. Enquanto ensino continuo buscando, reprocurando. Ensino porque busco, porque indaguei, porque indago e me indago. Pesquiso para constatar, constatando, intervenho, intervindo educo e me educo. Pesquiso para conhecer o que ainda náo conheço e comunicar ou anunciar a novidade. (FREIRE, 2008, p. 29).

Paim foi buscar na arte de desafinar o 'coro dos contentes' a desmistificação da ordem, anunciando a existência do conflito contínuo, afinal, "a dialética humana não sobrevive apenas com alimentação material” (DEMO, 1987, p. 21), que é o mesmo que dizer "nem só de pão vive o homem".

Não foi por acaso que o conferencista referiu-se a Gramsci. Porque, como explica Pedro Demo, Gramsci integra o rol de críticos do sistema interessados na mobilização política. Assim, “[...] não é praticável a mobilização política sem mobilizadores, sem organizadores e líderes, sem articuladores ideológicos que constroem a contra-ideologia” (DEMO, 1987, p. 75).

Ao analisar a posição do estado e dos governos republicanos, o professor Paim deixou evidente, mais uma vez, que a reforma sanitária é um campo de batalha ideológica e, diante do conteúdo de seu discurso, é quase impossível negar a natureza educadora do (seu) ato político, tampouco a natureza política do processo educativo (FREIRE, 1988) que ele duplamente encenou no Teatro Guararapes, em Recife (PE).

Ao final da conferência, ouviam-se comentários sobre o tema apresentado pelo preletor, e a conclusão sobre a necessidade da utopia para o resgate dos princípios da RSB. Mas, Hitlodeu adverte sobre os riscos para se chegar à 'ilha' sem aparatos teórico-práticos de segurança: "Outros rochedos ficam ocultos sob a água, e são por tal razão muito perigosos" (MORE, 2008, p. 53). Desse modo, somente os mais atentos às mudanças que configuram o 'transformismo' e a 'revolução passiva' no campo da saúde no Brasil poderão motivar e orientar os indivíduos para a procura desse caminho. E foi o que Paim, como acadêmico ainda engajado, tentou fazer na ABRASCO 2009, pois, como ensina o personagem de More (2008),
[...] só os naturais da ilha conhecem os passos navegáveis. Por isso quase nenhum navio estrangeiro se atreve a penetrar no porto sem um piloto utopiano. Aos próprios habitantes se tornaria perigosa a entrada, se não tivesse, na costa, certos pontos de referência que os orientassem. (MORE, 2008, p. 53).

A utopia nasce do desejo de construir coletivamente e democraticamente um novo 'fazer' em saúde e na formação para a saúde, o que pressupóe uma mudança na estrutura da sociedade, náo somente no campo acadêmico, mas nas esferas do econômico, do social, da política e da cultura. O recado de Paim reitera a importância da busca do saber e do fazer político por quem atua no campo da Saúde Coletiva, trazendo a 'praxis' mais uma vez para o centro das alternativas, pois, as conquistas institucionais na esfera da saúde pública não estão plenamente consolidadas, não são intocáveis, não se constituem simplesmente com a implantação e a ampliação gradativa de unidades e serviços nos diversos níveis de complexidade do sistema, quando o que está em jogo é o modelo de atenção à saúde ofertado, e, por consequência, a sua qualidade.

Como acadêmico, a posição adotada por Paim, em Recife (PE), induz a necessidade de reflexóes sobre o papel da academia, tanto na formação dos profissionais visando ao novo modelo assistencial, quanto no embate de natureza ideológica no que concerne à implementaçấo do sistema de saúde como reflexo de uma disputa no âmbito das políticas públicas.

\section{Utopia, pensamento científico e o papel dos atores na construção da saúde}

A postura do conferencista baiano no Congresso da ABRASCO 2009, onde o pensamento acadêmico-científico sempre predomina, estimula a seguinte reflexão: Que papel deve desempenhar hoje o universo acadêmico, os militantes da saúde coletiva na avaliação das políticas públicas que afetam a saúde como direito? Em que dimensão esses atores utilizam a estratégia utópica para pensar o contexto e intervir sobre ele? 
Essa estratégia utópica se elege, pressupóe a utopia no sentido do concreto, do possível como o resultado da ação política ou da práxis, portanto, mais para objetivo, uma busca coletiva, do que para um sonho individual. A própria ilha da Utopia é um lugar onde, para More (2008), as coisas acontecem mediante um esforço coletivo para a construção de um estado republicano aprimorado em garantir o bem-estar social, no qual a saúde se insere como prioridade, onde a desigualdade não existiria, pelo menos, no patamar que conhecemos. Esse conceito de utopia aproxima-se daquilo que Freire (1982) chama de "utopia revolucionária", dinâmica, e não estática; de seres vivos críticos e náo de mortos ou passivos frente às ordens e às imposiçóes de cada tempo e lugar.

Ao apresentar seu ponto de vista sobre o processo da RSB naquela manhá, Paim acenou com uma convicção utópica, contrária à acomodação, esta que configura o que Jaime Breilh chama de 'academicismo elegante', parcimonioso, sem propósito social. Muito antes, Darcy Ribeiro disse, em seu momento histórico, que "[...] a futilidade da pesquisa universitária é quase total do ponto de vista da escolha de opçóes políticas" (RIBEIRO, 2007, p. 89), demonstrando que a academia não está imune à inércia. Náo fora à toa que Breilh (2006) reafirmara o mesmo em relação à característica pós-moderna da produção científica acadêmica:

Essa circunstância levou-nos a afirmar que, na era atual, existe uma sagrada aliança entre o positivismo e o culturalismo, com o objetivo de reproduzir a hegemonia e cercear as mentes dos propfissionais e cientistas da saúde em geral, e da saúde pública em particular. (BREILH, 2006, p. 107).

Se diversos autores percebem essa ciscustância, é natural considerar que a postura de Jairnilson Paim no congresso da ABRASCO 2009 foi um misto de sinais e sintomas de uma angústia endêmica que se espraia do mundo acadêmico para a sociedade, e vice-versa.

Não há como desconsiderar, diante da postura de Jairnilson Paim, no ABRASCO 2009, a emergência de uma prática acadêmica emancipadora e emancipada, politicamente engajada na luta pelos princípios e diretrizes do SUS como resultado de conquistas mais amplas da sociedade brasileira. Nessa direção, retomamos a análise feita por Darcy Ribeiro ao referir-se à postura do cientificismo acadêmico contemporâneo:

Isso não só no plano da pesquisa cientifica, mas também no plano prático da formação profissional. Tome-se, por exemplo, o caso dos economistas. Para ser economista graduado, o jovem tem que levar em conta uma imensa parafernália, tem uma verdadeira lavagem de cérebro, que acaba por desvinculá-lo dos problemas reais de seu país. Simula-se fazer dele um analista cientifico isento, mas de fato ele é treinado para servir como contador zeloso da pecunia patrimonial ou como eficiente sonegador de impostos. Se acaso ele se dedica à pesquisa cientifica, raramente tem coragem de enfrentar qualquer problema relevante do plano social. Pensar numa economia que garanta a prosperidade generalizável a todos, para ele pareceria uma coisa que oscila entre o utópico e o subversivo. (RIBEIRO, 2007, p. 90).

Ribeiro (2007) nos fornece instrumentos para o entendimento da correlação entre o papel de quem faz a ciência, de quem educa e de quem é educado na manutenção ou não de estruturas conservadoras, chamando a atenção para a conduta comum de estudantes e professores que desmerecem a utopia e o caráter subversivo do homem na luta por direitos, neles contidos o direito à saúde e à qualidade de vida.

Quando surgiu no Teatro Guararapes para contrariar o 'coro dos contentes', o professor Paim reinstaurou uma antiga ordem esquecida de atores 'iracundos'. $\mathrm{Na}$ visão de Darcy Ribeiro os 'iracundos' são os intelectuais raivosos, "como o Gregório de Matos, que é uma beleza de iracundo". Mas existem também os intelectuais 'áulicos', uma forma mais numerosa, "[...] ajudante de ordens, aquele que está contente com o mundo tal qual é, e fazem o seu papel” (RIBEIRO, 2007, p. 125), papel que Paim parece nâo concordar, optando pela utopia e pela práxis no campo da saúde. 
Mas não se trata aqui de uma utopia fantasiosa. Contudo, de uma utopia mais próxima daquela descrita por Darcy Ribeiro na obra a 'Utopia Selvagem'. Assim, Ribeiro (2007) explica a sua opção utópica tomando por comparação as aspiraçóes de Thomas More:

Originalmente, no Thomas More, a utopia não era projeto, nem a minha utopia também é. Ela é apenas uma máquina de pensar, um contraste para obrigar a pensar, uma forma de quebrar a ilusão das falsas utopias que nos oferece o desenvolvimento progressista [...] Meu projeto utópico é para ser realizado aqui e agora. (RIBEIRO, 2007, p. 127).

É a utopia como combustível da ação crítica e transformadora da realidade de certa ordem que, sendo conservadora por princípio, se coloca na condição de eterna.

Paim apresentou o seu discurso aos veteranos e jovens a ponto de provocar-lhes um choque nas concepçóes, ou, no mínimo, alertá-los para o fato de que estar contente com o mundo tal qual é seria desconhecer o conteúdo do processo de construção e desconstrução do próprio mundo, do ponto de vista de certa matriz ideológica que não aceita a vida social como processo, e, portanto, como mutável.

O resgate da luta coletiva pela reforma sanitária passa, impreterivelmente, pela reformulação do modelo teórico-prático do ensino e do caráter transformador da pesquisa científica, bem como pela gestão do trabalho que possibilite a autonomia dos que constroem e reconstroem a saúde cotidianamente. Uma luta utópica implica em ruptura com a proposta de universidades formadoras de mão de obra 'qualificada' para atender à lógica da produtividade fabril, quando a sociedade precisa de trabalhadores da saúde críticos e autônomos, envolvidos com a realidade e mais atuantes do ponto de vista das proposiçóes e da integração dos múltiplos campos do conhecimento, sem a qual não se faz promoção da saúde.

Quando se atinge a democracia, novas formas coercitivas surgem no lugar das ditaduras, geralmente, mais sutis, mas não menos limitantes do pensamento e da ação. Uma sutileza perigosa que mina a estrutura em formação das grandes conquistas sociais, a exemplo do SUS, que agora precisa de 'defesa'. A tarefa mais árdua não é questionar o momento, posto que as contradiçóes de um mercado capitalista são cada vez mais perceptíveis no globo. A lógica privada da saúde vai ganhando força, quando os novos atores não se libertam das práticas limitantes da emancipação e da organização do pensamento contra-hegemônico, e vão se tornando cúmplices do que antes combatiam. Essa parece ser a etapa mais complexa a ser transposta, por sua dialética. No auge do 'Ctrl+X' e do 'Ctrl+V', assistimos à hegemonia da alienaçáo e do descompromisso com o saber que ainda campeia o universo das escolas. Essa percepção, entretanto, não é nova:

Quando voltei à universidade brasileira, levei um susto; havia estudante de antropologia que nunca tinha lido uma obra inteira. É preciso lutar contra o baixo clero que tomou conta do mundo universitário e ajudou a criar a geração xérox [...] Estou velho, os jovens é que devem mudar tudo isso. (RIBEIRO, 2007, p. 180).

De tudo ouvido no Teatro Guararapes, naquela manhã, ficou que a utopia não é apenas um desejo maior, é uma estratégia para o fomento do pensamento e da ação, que deve acontecer em qualquer canto do mundo. A utopia pode ser até mesmo um lugar, como imaginou Thomas More, cinco séculos atrás. Pode ser o município, o estado, o país. Até mesmo pode ter sido o Teatro Guararapes, onde o professor nordestino fez um brilhante discurso utópico em favor da RSB. E, sendo ela tão importante, cabe recordar a mensagem de Oscar Wild: "Um mapa que não tem a localização da Utopia, não merece ser guardado", porque, “[...] uma característica do ser humano é a de ser um fabricante de utopias" (WILD apud BREILH, 2006, p. 165).

Para se chegar ao sonho essencial da reforma sanitária, é preciso que se tenha como meta a utopia, o lugar da práxis com toda a sua historicidade, com toda a sua territorialidade. Se, em função das barreiras 'naturais', não for possível chegar a alcançá-la, pelo menos, em algum sonho, pedaço de terra, assoalho de 
pedra, tocaremos. Mas, o que tem de bom na Ilha da Utopia? Segundo Hitlodeu, todo morador da Utopia já possui "[...] o direito de alimentar-se e a tirar da terra o seu sustento" (MORE, 2008, p. 65). Os utopianos também têm acesso universal aos cuidados de saúde, podendo escolher até em que condiçôes devem morrer, segundo Rafael Hitlodeu. E tudo isso foi instituído numa ilha. Imagine no século XVI...

Por fim, não estariam nessa 'ilha', em exercício, alguns direitos universais, princípios e diretrizes do nosso sistema de saúde, bases da Reforma Sanitária Brasileira?

\section{Referências}

BREILH, J. Epidemiologia crítica: ciência emancipadora e interculturalidade. Rio de Janeiro: FIOCRUZ, 2006.

DEMO, P. Avaliação Qualitativa. 5.ed. Campinas: Autores Associados, 1987.

FREIRE, P. Ação cultural para a liberdade e outros escritos. 6.ed. Rio de Janeiro: Paz e Terra, 1982.

A importância do ato de ler. 21.ed. São Paulo: Autores Associados: Cortez, 1988.

Pedagogia da autonomia: saberes necessários à prática educativa. 38.ed. São Paulo: Paz e Terra, 2008.
MORE, T. A Utopia. São Paulo: Martin Claret, 2008.

OLVIEIRA, F. O avesso do avesso. Piauí, São Paulo, n. 37, 2009.

PAIM, J. S. Reforma Sanitária Brasileira: contribuição para uma compreensão e crítica. Salvador: ADUFBA; Rio de Janeiro: FIOCRUZ, 2008.

O que é o SUS. Rio de Janeiro: FIOCRUZ, 2009.

RIBEIRO, D. Encontros. Rio de Janeiro: Beco do Azougue, 2007.

PUTNAM, R. D.; LEONARDI, R.; NANETTI, R. Y. Comunidade e democracia: a experiência da Itália moderna. 4.ed. Rio de Janeiro: FGV, 2005.

Recebido para publicação em Setembro/2011

Versão final em Abril/2013

Conflito de interesse: não houve

Suporte financeiro: inexistente 